\title{
Reflexões teóricas sobre a construção paradigmática da Ciência da Informação: considerações acerca do(s) paradigma(s) cognitivo(s) e social
}

\author{
Jonathas Luiz Carvalho Silva \\ Maria Giovanna Guedes Farias \\ Universidade Federal da Bahia - UFBA, Brasil
}

ANÁLISE / ANALYSIS

\begin{abstract}
Resumo
Trata da investigação dos processos teóricos e epistemológicos que influenciam na formação do paradigma cognitivo da Ciência da Informação $(\mathrm{Cl})$, observando ainda a emergência do paradigma social no âmbito da análise de domínio e hermenêutica da informação. Para isso, adotou-se as reflexões de autores clássicos e contemporâneos, a exemplo de Thomas Kuhn, Boaventura Santos, Capurro, Hjørland e Albrechtsen. Conclui-se que a percepção de paradigma na $\mathrm{Cl}$ é uma questão consolidada, todavia o paradigma social ainda está em processo de construção, o que permitirá a criação de percepções, interpretações e contribuições a fim de preencher lacunas deixadas por outros paradigmas.
\end{abstract}

Palavras-chave

Paradigmas ; Paradigma social ; Paradigma cognitivo ; Ciência da Informação ; Epistemologia ; Análise de domínio ; Hermenêutica da informação

Theoretical reflections on the paradigmatic construction of Information Science: considerations about the (s) paradigm (s) cognitive (s) and social

\begin{abstract}
It presents a research about the theoretical and epistemological processes that influence the formation of the cognitive paradigm of Information Science (IS), noting the emergence of social paradigm within the domain analysis and hermeneutics of information. For this, we adopted the reflections of classical and contemporary authors, like Thomas Kuhn, Boaventura Santos, Capurro, Hjørland and Albrechtsen. We conclude that the perception paradigm in IS is a consolidated issue, however the social paradigm is still under construction, which will allow the creation of perceptions, interpretations and contributions in order to fill gaps left by other paradigms.
\end{abstract}

Keywords

Paradigms ; Paradigm social ; Cognitive paradigm ; Information Science ; Epistemology ; Analysis domain ; Hermeneutics of information 


\section{Introdução}

A presente comunicação objetiva investigar os processos teóricos e epistemológicos que influenciam na formação do paradigma cognitivo e social da Ciência da Informação $(\mathrm{Cl})$, atentando ainda para a emergência do paradigma social no âmbito da análise de domínio e hermenêutica da informação. Para isso, apresenta-se a noção de paradigma e suas considerações teórico-conceituais, discorre-se a respeito da pluralidade paradigmática da $\mathrm{Cl}$ analisando os paradigmas cognitivos e suas influências teóricas, para logo em seguida promover reflexão sobre a busca do paradigma social da $\mathrm{Cl}$.

Inicia-se essa revisão de literatura com o filósofo Thomas Kuhn expoente na busca da definição de paradigma, utilizando-se ainda Boaventura Santos para questionar sobre o paradigma dominante e o paradigma emergente no contexto da ciência moderna e da ciência pós-moderna. Prossegue-se com as ponderações de Capurro que analisa os paradigmas físico, cognitivo e social na perspectiva da Cl. Aponta-se também os estudos de Hjørland e Albrechtsen sobre o paradigma sócio-cognitivo e sua efetiva aplicabilidade.

A visão desses e de outros autores adotados nesse trabalho, proporcionou o encaminhamento para as considerações finais, onde ressalta-se que o paradigma cognitivo não favorece mais a busca por soluções para problemas e desafios de cunho social apresentados pela $\mathrm{Cl}$. A proposta, para a construção de novos conhecimentos, seria a consolidação do paradigma social, permitindo a criação de percepções, interpretações e contribuições a fim de preencher lacunas deixadas por outros paradigmas, que não podem ser mais visualizados como dominantes.

\section{Da noção de paradigma: algumas considerações teórico-conceituais}

Ao tratar de paradigma, Thomas Kuhn aparece como referência indispensável e como um autor que provocou reflexões sobre as revoluções nas estruturas científicas na perspectiva de alguns pensadores, e ao mesmo tempo como alguém que não surpreendeu outros pesquisadores com suas ponderações, os quais não valorizaram 0 empenho desse filósofo em conceituar o termo paradigma e contextualizá-lo de acordo com os padrões dominantes da cultura dos praticantes da ciência. Kuhn (1992) traz em seu livro diversas definições a respeito de paradigma, explicando em seu posfácio a motivação para isso. Nessa comunicação, tomamos desse autor duas vertentes, ou seja, uma definição inicial e uma posterior que nos levou a um entendimento do que seriam paradigmas: "[...] realizações científicas universalmente reconhecidas que, durante algum tempo, fornecem problemas e soluções modelares para uma comunidade de praticantes de uma ciência" (p.13) comunidade esta, que "[...] consiste em homens que partilham um paradigma" (p. 219) e que se esforçaram, tendo ou não sucesso, para contribuir com a evolução da ciência por meio de suas pesquisas.

Para definir e caracterizar um paradigma González (2005, p. 10) ressalta que, deve-se pensar em onze aspectos descritos abaixo, que vão do sociológico passando pela natureza epistemológica até as normas de atuação convencionais:

[...] (1) caráter sociológico, isto é, a referência para a comunidade científica que o assume; (2) demanda consensual, que se refere à necessidade de aceitação geral e não imposta de modos básicos de ação; (3) historicidade, reconhecimento da vigência temporal; (4) natureza estrutural e sistêmica, referindo-se à presença de uma organização harmoniosa, completa e integrada diferentes componentes; (5) instrumentalidade demarcadora, a delimitação de uma área de estudo; (6) estatuto metodológico, convênios como os meios para lidar com a parte da realidade em que você tem interesse; (7) contexto de legitimação, os critérios de avaliação de propostas de soluções para os problemas abordados; (8) linguagem, formas e meios de expressão e comunicação convencionalmente aceitos; (9) um aspecto organizacional, as hierarquias do sistema, e relações inter e intracomunitárias; (10) natureza epistemológica, formas de produzir conhecimento privilegiado dentro da comunidade e, (11) caráter prescritivo, padrões de desempenho. (Tradução nossa). 
O percurso e a descrição desses aspectos levam à percepção de que há sentido denominar, como o fez Kuhn (1992, p. 83), um paradigma como um modelo ou padrão aceitos, mesmo que a primeiro momento ele pareça limitado. Um modelo possibilita, a partir da aquisição de seu status, apontar soluções de problemas, o que proporciona ao paradigma obter sucesso, ou melhor, "[...] uma promessa de sucesso e a ciência normal ${ }^{1}$ atualiza essa promessa e potencializa o conhecimento dos fatos apresentados pelo paradigma". De acordo com Kuhn, existe um lado bom do paradigma quando os cientistas são impelidos a investigar uma parcela da natureza com profundidade. "Se o paradigma não é mais efetivo ele é abandonado. Além disso, os cientistas mostram-se intolerantes com teorias inventadas por outros, ou seja, quem não se ajusta ao paradigma dominante nem é visto". (KUHN, 1992, p. 83).

É por isso, que na arena da competição de qual será o paradigma dominante, Kuhn (1992, p. 35) explica que uma teoria deve ser melhor do que suas competidoras, mas não precisa explicar todos os fatos com os quais pode ser confrontada. "Na ausência de um paradigma ou de algum candidato a paradigma, todos os fatos que possivelmente são pertinentes ao desenvolvimento de determinada ciência têm a probabilidade de parecerem igualmente relevantes". Isso ocorre porque, segundo Ostermann (1996), no contexto de uma revolução científica, onde pode surgir uma nova tradição de ciência normal, um processo cumulativo obtido através de uma articulação do velho paradigma pode fica distante de acontecer. O que realmente ocorre é "[...] uma reconstrução da área de estudos a partir de novos princípios, que altera algumas das generalizações teóricas mais elementares do paradigma, bem como muitos de seus métodos e aplicações." (OSTERMANN, 1996, p. 191).

Kuhn (1992, p. 26-27) ainda alerta que o surgimento ou a criação de novas teorias provoca a mesma resposta por parte de alguns especialistas, que veem sua área de competência infringida por essas teorias. "Para esses homens, a nova teoria implica uma mudança nas regras que governam a prática anterior da ciência normal. Por isso, a nova teoria repercute inevitavelmente sobre muitos trabalhos científicos já concluídos com sucesso." E essa repercussão, ocasionada pelas novidades fundamentais de fatos ou teorias, pode ser vista como uma forma de enriquecer o mundo do cientista de forma qualitativa e quantitativamente. "A competição entre segmentos da comunidade científica é o único processo histórico que realmente resulta na rejeição de uma teoria ou na adoção de outra”. Kuhn (1992) também aponta para uma 'dura' realidade que os cientistas têm de se submeter, pois os que não desejam ou não são capazes de acomodar seu trabalho ao novo paradigma (uma definição nova e mais rígida do campo de estudos) terão de atuar isoladamente ou unir-se a algum grupo.

Ao tratar de paradigma dominante, Santos (1988, p. 48), ressalta que sendo um modelo global, a nova racionalidade científica é também um modelo totalitário, ao negar o caráter racional a todas as formas de conhecimento que não se guiam pelos seus princípios epistemológicos e pelas suas regras metodológicas. "É esta a sua característica fundamental e a que melhor simboliza a ruptura do novo paradigma científico com os que o precedem". Em relação a essa ruptura, Capra (1996) entende que o paradigma que está retrocedendo dominou a nossa cultura por várias centenas de anos, modelando nossa moderna sociedade ocidental e influenciando significativamente o restante do mundo.
Esse paradigma consiste em várias ideias e valores entrincheirados, entre os quais a visão do universo como um sistema mecânico composto de blocos de construção elementares, a visão do corpo humano como uma máquina, a visão da vida em sociedade como uma luta competitiva pela existência, a crença no progresso material ilimitado, a ser obtido por intermédio de crescimento econômico e tecnológico, e - por fim, mas não menos importante - a crença em que uma sociedade na qual a mulher é, por toda a parte, classificada em posição inferior à do homem é uma sociedade que segue uma lei básica da natureza. Todas essas suposições têm sido decisivamente desafiadas por eventos recentes. E, na verdade, está ocorrendo, na atualidade, uma revisão radical dessas suposições. (CAPRA, 1996, p. 16).

A partir dessas revisões novos valores, ações fazem surgir um novo paradigma, talvez o que Boaventura Santos chama de paradigma emergente, o paradigma da ciência pós-moderna, como ele denominou. Nesse contexto, é preciso perceber que o paradigma está impregnado de valores, "[...] mesmo que grande parte das pesquisas detalhadas possa não depender explicitamente do sistema de valores do cientista, [...] que é o responsável por suas pesquisas não apenas intelectual, mas também moralmente”. (CAPRA, 1996, p. 20). 
Para surgir um paradigma emergente é preciso que o paradigma dominante esteja em crise profunda e irreversível, o que ocasionado, conforme Santos (1988, p. 54) pelo resultado interativo de uma pluralidade de condições sociais e condições teóricas. $\mathrm{O}$ autor observa que a "[...] identificação dos limites, das insuficiências estruturais do paradigma científico moderno é o resultado do grande avanço no conhecimento que ele propiciou. $O$ aprofundamento do conhecimento permitiu ver a fragilidade dos pilares em que se funda." Nesse espaço, surge a configuração do paradigma que se anuncia no horizonte obtida por via especulativa, fundada nos sinais que a crise do paradigma atual emite. "Sendo uma revolução científica que ocorre numa sociedade ela própria revolucionada pela ciência, o paradigma a emergir dela não pode ser apenas um paradigma científico, tem de ser também um paradigma social." (SANTOS, 1988, p. 60).

A substituição de um paradigma por outro, de um velho por um novo, requer um período de crise revolucionária, que pode durar por um longo período, o tempo que requer uma revolução científica. "O novo paradigma redefine os problemas e as incongruências até então insolúveis e dá-lhes uma solução convincente e é nessa base que se vai impondo à comunidade científica." Na revolução pelo embate para a consolidação do novo paradigma, "[...] as provas cruciais aduzidas em favor do novo paradigma podem facilmente ser consideradas ridículas, triviais ou insuficientes pelos defensores do velho paradigma". Por isso, "[...] o diálogo entre os cientistas tende para o monólogo na proporção da incomensurabilidade dos paradigmas em confronto". (SANTOS, 1978, p. 28). Um combate entre o paradigma dominante e o paradigma emergente, onde a ciência moderna que desconsiderou 0 conhecimento proveniente do senso comum, agora dá lugar à ciência pós-moderna que "[...] procura reabilitar o senso comum por reconhecer nesta forma de conhecimento algumas virtualidades para enriquecer a nossa relação com o mundo." (SANTOS, 1988, p. 70).

O que se percebe é o empenho dos pesquisadores em inserir no discurso científico a questão social, ou seja, a vontade de uma socialização da ciência, a necessidade da visão global, holística, a preocupação com a ética e a moral nas pesquisas, e a responsabilidade em dividir com a sociedade os progressos obtidos por meio das pesquisas. Essa tendência anunciada por Boaventura já está sendo empregada em várias áreas, a exemplo da Ciência da Informação (Cl), que de acordo com Capurro (2003, p. 3), "[...] nasceu com um paradigma físico, questionado por um enfoque cognitivo idealista e individualista, sendo este por sua vez substituído por um paradigma pragmático e social."

A Ciência da Informação inicia-se como teoria da information retrieval baseada numa epistemologia fisicista. Torna-se evidente que, no campo da $\mathrm{Cl}$, o que esse paradigma exclui é o papel ativo do sujeito cognoscente, ou de forma mais concreta, do usuário, no processo de recuperação da informação científica, em particular, bem como em todo processo informativo e comunicativo, em geral. Não por acaso, essa teoria refere-se a um "receptor" (receiver) da mensagem. Não é de se estranhar que os limites dessa metáfora hajam conduzido ao paradigma oposto, o cognitivo. [...] Isso nos leva à ontologia e à epistemologia de Karl Popper que influenciaram diretamente o paradigma cognitivo proposto por B. C. Brookes $(1977,1980)$, entre outros. A ontologia popperiana distingue três "mundos": o físico, o da consciência ou dos estados psíquicos, e o do conteúdo intelectual de livros e documentos, em particular o das teorias científicas. Popper fala do "terceiro mundo" como um mundo de "objetos inteligíveis" ou também de "conhecimento sem sujeito cognoscente". (CAPURRO, 2003, p. 8-9).

Apesar desse enfoque social, Capurro (2003, p. 9) explica que, sua "perspectiva permanece cognitiva no sentido de que se trata de ver de que forma os processos informativos transformam ou não o usuário, entendido como sujeito cognoscente possuídos de modelos mentais do mundo exterior", que durante processo informacional são transformados. Esse paradigma considera a informação como sendo algo separado do usuário, vendo-o distante dos condicionamentos sociais e materiais do existir humano. "É essa visão reducionista que é criticada por Bernd Frohmann, que considera o paradigma cognitivo não só como idealista, mas também como associal." (CAPURRO, 2003, p. 10).

A seguir aprofundaremos essa discussão em torno dos paradigmas cognitivos e suas influências na $\mathrm{Cl}$, para em seguida empreitarmos uma reflexão em busca do paradigma social dessa área, um paradigma definido por Capra (1996, p. 16) como "[...] uma constelação de concepções, de valores, de percepções e de práticas compartilhados por uma comunidade, que dá forma a uma visão particular da realidade, a qual constitui a base da maneira como a comunidade se organiza". 


\title{
3. Da pluralidade paradigmática da $\mathrm{Cl}$ : análise sobre paradigma(s) cognitivo(s) e suas influências teóricas
}

As noções de paradigma desenvolvidas por Kuhn (1994), Santos (1988) e outros estudiosos têm sido amplamente aplicadas/adaptadas em diversas áreas do conhecimento, como a Filosofia, Educação, Psicologia, Sociologia, Comunicação, Ciência da Informação, etc. É possível afirmar que o uso deliberado do termo paradigma na $\mathrm{Cl}$ apresenta duas interfaces opositivas: a primeira indica como prerrogativa um processo de amadurecimento científico e a segunda demanda a necessidade de afirmar uma cientificidade da área, o que pode deliberar certo 'banalismo teórico' ou 'inconsistência científica'. Wersig (1993, p. 230, tradução nossa) revela alguns indícios da inserção reflexiva/aplicativa sobre paradigmas na $\mathrm{Cl}$ ao afirmar que:

\begin{abstract}
É dado como fato que há alguma coisa como 'informação' que é necessária e que eles se oferecem para solucionar o problema. Mas argumenta que as organizações sociais e os sistemas tecnológicos sempre apareceram na sociedade como soluções a necessidades a serem atendidas [...], mas nunca se constituíram em ciências no sentido tradicional. Esta talvez seja a razão por que os cientistas da informação sintam tanta urgência em ter um paradigma nas mãos para demonstrar sua maturidade científica.
\end{abstract}

É possível observar que Ciência da Informação, enquanto campo do conhecimento estabelece linhas de investigação no âmbito da informação, intrinsecamente ligadas a organizações e sistemas tecnológicos. Este ideário de informação é visto, por sua vez, como fenômeno de solução de problemas e satisfação de necessidades que se afirma como atividade mercadológica e não na constituição de uma ciência propriamente dita, o que confirma que a $\mathrm{Cl}$ incorre no uso do termo paradigma para promover uma efetiva compreensão dos estudos sobre organizações e sistemas tecnológicos, como sendo um conjunto de fundamentos teóricos e empíricos promovendo perspectivas mais amplas de justificação da cientificidade da área.

Aliás, é preciso afirmar que o advento da $\mathrm{Cl}$, além de está ligado a um conjunto de teorias e áreas do conhecimento, como Biblioteconomia, Documentação, Ciências Cognitivas, Recuperação de Informação, Teorias Matemática e Sistêmica da Informação, entre outras (CARVALHO SILVA; FREIRE, 2012), também está conectado a um conjunto de terminologias/teorias que se constituíram em períodos similares de institucionalização da $\mathrm{Cl}$, como: disciplinaridade e todos os seus prefixos gnosiológicos, como pluridisciplinaridade, transdisciplinaridade e, principalmente, a interdisciplinaridade e paradigma, o que ratifica o apego da $\mathrm{Cl}$ em axiomas fundamentos social e cientificamente para justificar sua maturidade científica.

O fato é que independente do termo paradigma indicar possibilidades de amadurecimento científico da $\mathrm{Cl}$ (ou não) se constitui como fundamento sine qua non da cultura científica da área, pois dinamiza seus pressupostos teóricos e concebe frutos de reflexão histórica e social. De acordo com Capurro (2003, p. 3), a Cl "[...] nasceu com um paradigma físico, questionado por um enfoque cognitivo idealista e individualista, sendo este por sua vez substituído por um paradigma pragmático e social."

É pertinente destacar que esses paradigmas em termos de finalidade são considerados excludentes, mas como fundamentos teóricos, históricos e epistemológicos da $\mathrm{Cl}$ se complementam, visto que o paradigma físico se constituiu a partir do contexto aplicativo da recuperação de informação especialmente entre as décadas de 60 e 80 apresentando como principal linha de estudos o enfoque essencial nos sistemas de informação relegando a um plano inferior o usuário, enquanto o paradigma cognitivo tem seu advento em meados da década de 70 (SARACEVIC, 1995) apresentando um olhar mais cauto para o usuário da informação, mas sem considerar suas perspectivas sociais e materiais (FROHMANN, 1995) e o paradigma social se estabelece a partir de meados da década de 90 permitindo afirmar que ainda é um paradigma em construção na $\mathrm{Cl}$. 
Com efeito, a prioridade neste tópico é discutir sobre os paradigmas cognitivos da $\mathrm{Cl}$. Contudo, por quais motivos se dá a utilização plural do termo 'paradigmas cognitivos' e não em sua singularidade terminológica 'paradigma cognitivo', uma vez que é conhecido como sendo um paradigma da Cl? A resposta reside no fato de que embora exista um paradigma cognitivo da $\mathrm{Cl}$, a sua constituição ocorre a partir de um conjunto de correntes teóricas que estabelecem nichos de multiplicidade perceptiva do paradigma cognitivo.

Logo, é possível dividir o paradigma cognitivo da $\mathrm{Cl}$ em dois níveis: o nível macro que é referente à postulação de um paradigma cognitivo referencial na Cl, conforme elucidado por vários autores, como Brookes (1977, 1980), Belkin (1980), Ingwersen (1992), entre outros e o nível micro que é referente a diversas correntes teóricas que influenciam o paradigma cognitivo macro e formam novos paradigmas cognitivos micros aplicados a $\mathrm{Cl}$, tais como: paradigma cognitivo behaviorista, paradigma cognitivo funcionalista, paradigma cognitivo estruturalista.

O paradigma cognitivo macro pode ser entendido como uma contextualização que assume o usuário como elemento primordial no processo de acesso, uso e apropriação da informação, e tem como fator institucionalizador, conforme afirma Ingwersen (1992), a Conferência de Copenhagen, ocorrida em 1977, onde houve várias exposições de pesquisas realizadas por autores consagrados na Ciência da Informação e que contribuíram diretamente para o desenvolvimento do paradigma cognitivo, sendo pertinente destacar algumas.

A primeira é de Marc de May (1977) que apresentou a proposta da visão cognitiva centrada no usuário, na qual qualquer processamento da informação perceptivo ou simbólico deve ser mediado por um sistema de categorias ou conceitos, pelas quais as ferramentas do processamento da informação sejam um modelo de seu mundo. A segunda é de Belkin (1980) que desenvolve a 'teoria dos estados anômalos do conhecimento' significando que a busca de informação tem origem a partir de uma necessidade ou situação problemática e a publicação. ${ }^{2}$ Em outras palavras, essa teoria, segundo Capurro (2003), parte da premissa de que a busca de informação tem sua origem na necessidade "need", que surge quando existe o mencionado estado cognitivo anômalo, no qual o conhecimento ao alcance do usuário, para resolver o problema, não é suficiente.

A terceira é de Brookes (1980) precursor do paradigma cognitivo, que desenvolveu uma concepção teórica baseada nos três mundos de Karl Popper como uma forma de estudar os processos de objetividade e mensurabilidade da informação. ${ }^{3}$ Brookes (1980, p. 128) em seu artigo intitulado The Foundations os information science afirma que:

\begin{abstract}
O Mundo 3 de Popper deve recomendar-se à biblioteconomia e à ciência da informação porque, pela primeira vez, oferece uma abordagem racional às suas atividades profissionais, a qual pode ser expressa noutros termos que não meramente práticos. [...] E a tarefa teorizadora consiste em estudar as interações entre o mundo 2 e o 3, descrevê-los e explicá-los se possível e também ajudar a organizar mais o conhecimento que o documento com vista a um uso efetivo.
\end{abstract}

Brookes busca aplicar o terceiro mundo popperiano referente à proposição de um conhecimento objetivo, a partir da interação entre os dois primeiros mundos que levou a constituição da equação fundamental da Ciência da Informação. Desse modo, a equação fundamental da Ciência da Informação foi concebida como associação de elementos matemáticos, lógicos e filosóficos, visando aliar o espectro conteudístico das ciências sociais com as ciências naturais. Marteleto (1987, p. 172) quando fala sobre a equação de Brookes traduz que "[...] implica que essas entidades (informação e conhecimento) são mensuráveis, podendo ser medidas através das mesmas unidades, isto é, a informação e o conhecimento são fenômenos do mesmo tipo. Assim definida, a informação é um pequeno bit do conhecimento". Em suma, pode-se afirmar que Brookes busca uma aproximação do paradigma cognitivo com os paradigmas das ciências naturais, estabelecendo como ponto integrados os estudos métricos da informação, especialmente contemplando as Leis de Bradford, Zipf e Lotka.

Já em relação aos paradigmas cognitivos micros, que dão suporte epistemológico ao paradigma cognitivo macro, destacam-se basicamente: o paradigma cognitivo no âmbito behaviorista, paradigma cognitivo no âmbito do processamento da informação, paradigma cognitivo no âmbito funcionalista e o paradigma cognitivo no âmbito estruturalista.

Em primeiro lugar, o behaviorismo, oriundo do termo inglês 'behavior' (comportamento), é uma teoria que está eminentemente ligada aos processos de comportamento do ser humano. O precursor do behaviorismo é o estudioso dos Estados Unidos John Watson (1912) que desenvolveu um artigo intitulado 'Psicologia como os behavioristas a 
vêem' e compreende que o behaviorismo pretende que o domínio da psicologia seja o comportamento do ser humano e considera que a consciência não é um conceito definível nem utilizável.

O behaviorismo tem sido aplicado de forma intensa na Ciência da Informação como prerrogativa do paradigma cognitivo a partir de alguns fatores: estudo de usuários da informação, sistemas de recuperação da informação e usabilidade. Ressalta-se que, a usabilidade tanto é um subsídio do paradigma cognitivo behaviorista no âmbito dos estudos de usuários da informação, quanto dos sistemas de recuperação da informação. No que tange aos estudos de usuários, o paradigma cognitivo behaviorista tem sido bastante aplicado para conceber comportamentos de busca, acesso e uso da informação pelo usuário, assim como para compreender o planejamento, organização e os serviços dos centros de informação. Como afirma Wilson-Davis (1977), as investigações relativas aos estudos de usuários abordam basicamente dois tipos de comportamento: estudos centrados na biblioteca, a investigação de como as bibliotecas e os centros de informação são utilizados; e os estudos centrados no usuário, como um grupo particular de usuários obtém a informação necessária para conduzir o seu trabalho.

O ideário do paradigma cognitivo behaviorista aplicado aos estudos de usuários tem grande ênfase nos discursos e práticas das décadas de 60 a 80 . Na década de 60 , os estudos de usuários de bibliotecas se preocupavam em identificar notadamente comportamentos concernentes à frequência de uso de determinado material e outros comportamentos de forma puramente quantitativa, e não detalhavam os diversos tipos de comportamentos informacionais. (BAPTISTA; CUNHA, 2007). Já na década de 70 identificava uma perspectiva comportamental de que o uso da informação dependia da facilidade de acesso e que, nem sempre, a informação utilizada era a melhor. (FIGUEIREDO, 1994). Na década de 80 é possível identificar a consolidação do paradigma cognitivo behaviorista nos estudos de usuários da informação quando concebe como objetivo possibilitar o planejamento de serviços ou sistemas de informação, que fossem capazes de satisfazer os usuários da informação a partir da identificação de seus comportamentos e necessidades de informação. (PINHEIRO, 1982). 4

No que se refere aos sistemas de recuperação de informação, há uma forte ênfase no contexto do paradigma cognitivista behaviorista quando aborda o indivíduo a partir de processos psicológicos com olhar da organização e tratamento da informação, com vistas a uma recuperação eficiente e eficaz. (NASCIMENTO, 2006).

A usabilidade é uma linha de estudos que se desenvolve no contexto dos estudos de uso e usuários da informação, com vistas a compreender o comportamento dos usuários que utilizam sistemas de recuperação da informação. Em outras palavras, conforme revela Carvalho Silva (2013) a usabilidade é fruto de estudos desenvolvidos para sistemas de informação automatizados, visando observar como os usuários agem e interagem de forma mental e física com o produto.

Em segundo lugar, o paradigma cognitivo no âmbito do processamento da informação surge diante do advento das tecnologias de informação e de comunicação após a Segunda Guerra Mundial como fenômeno de contraposição ao paradigma behaviorista, concebendo novos fundamentos para os estudos dos processos mentais e do desenvolvimento cognitivo, sendo firmado como paradigma computacional. Vale destacar que o economista $\mathrm{H}$. A. Simon e o matemático e físico A. Newell, representantes desse paradigma computacional, afirmavam que qualquer máquina capaz de processar símbolos poderia também simular os processos mentais. Nesta abordagem, a inteligência era considerada enquanto um processo de busca, por meio de heurísticas eficientes, visando à resolução de problemas. (CARVALHO, 1998).

Isso significa dizer que este paradigma apresenta uma perspectiva eminentemente simbolista, primando por perceber a mente como um sistema lógico e não físico (por isso é possível dizer que este paradigma não está associado ao paradigma físico da $\mathrm{Cl}$ e sim ao cognitivo) a partir de uma relação efetiva entre a menta humana e o computador. É preciso enfatizar que a consolidação deste paradigma está intrinsecamente concatenada as influências da Computação, assim como das Ciências Cognitivas e da Inteligência Artificial.

Em terceiro lugar, o paradigma cognitivo no âmbito funcionalista tem sido fortemente aplicado/estudado na $\mathrm{Cl}$ a partir de três percepções essenciais:

- a primeira é de Malinowski (1977, p.155) quando afirma que "[...] a função significa sempre a satisfação de uma necessidade, desde a simples ação de comer até a 
execução sacramental, em que o fato de receber a comunhão se inscreve em todo um sistema de crenças, determinadas pela necessidade cultural [...]". Logo, o paradigma cognitivo funcionalista na $\mathrm{Cl}$ prima pela ideia de que todo centro de informação deve satisfazer necessidades de informação dos usuários;

- a segunda é de Merton que estabelece uma tipificação funcional de um sistema em funções manifestas e funções latentes. As funções manifestas são "[...] aquelas consequências objetivas que contribuem ao ajuste e adaptação do sistema as quais são pretendidas e reconhecidas pelos participantes no sistema" (MERTON, 1957, p.51). Já as funções latentes podem ser definidas como sendo "[...] aquelas que não são nem pretendidas nem reconhecidas [pelos participantes no sistema]" (MERTON, 1957, p.51). Aplicada ao paradigma cognitivo funcionalista da $\mathrm{Cl}$ as concepções de Merton se estabelecem a partir de uma função manifesta que se configura nos estudos sobre centros de informação (e sua equipe) no desenvolvimento de práticas de mediação, gestão, planejamento, implementação de serviços, uso de tecnologias, entre outras atividades, assim como em estudos sobre as funções dos sistemas de recuperação de informação e a partir de uma função latente que consiste em investigar como os usuários acessam, usam e se apropriam da informação e quais necessidades e nível de satisfação confirmam diante dos serviços e práticas do centro de informação.

- a terceira é de Von Bertalanffy, o criador da Teoria Geral dos Sistemas (TGS), também chama de Teoria Sistêmica da Informação ou ainda de novo funcionalismo, que conceitua sistema como um conjunto de elementos em interação. (BERTALANFFY, 1977). Araújo (2009) indica que a teoria sistêmica tem sido abordada na Ciência da Informação em duas grandes perspectivas: a primeira, em nível macro, está relacionada às teorias funcionalistas a respeito da função da informação na sociedade e a segunda se relaciona com o desenvolvimento das teorias sobre os sistemas de informação.

Finalmente, em relação ao paradigma cognitivo estruturalista, tem como base as ideias de Levi-Strauss (1967) em que um modelo deve oferecer um caráter de sistema considerando que: todo modelo deve pertencer a um grupo de transformações (grupo de modelos); previsão de como reagirá o modelo em caso de modificação de um elemento; é necessário que o modelo seja construído de tal modo que seu funcionamento possa explicar todos os fatos observados.

Destarte, o paradigma cognitivo estruturalista pode ser entendido na $\mathrm{Cl}$ para o desenvolvimento de estudos que agreguem algumas ligações/relações: entre processos de informação; entre fluxos de informação; entre procedimentos para gestão da informação; as relações entre atividades de organização e tratamento da informação; interação entre usuário e centro de informação; relações entre usuários e profissionais da informação.

\section{Em busca do paradigma social na Ciência da Informação: algumas considerações}

Diante da análise concebida sobre os paradigmas cognitivos é possível evidenciar sua relevância para a fundamentação teórica, histórica e epistemológica da $\mathrm{Cl}$. Todavia, embora muito relevantes para a área, os paradigmas cognitivos não satisfazem mais algumas perspectivas de estudos da área, o que demanda a necessidade da construção do paradigma social, visando promover respostas para novos problemas e construção de novos conhecimentos na $\mathrm{Cl}$.

E por quais motivos o paradigma cognitivo não responde mais algumas questões/problemas levantadas pela $\mathrm{Cl}$, assim como há uma designação emergente de um paradigma social? Alguns fatores podem ser considerados:

- a) a necessidade de um paradigma que tenha como foco de estudos central o processo de construção COM o usuário e não apenas PARA o usuário (CARVALHO SILVA, 2012); 
- b) o paradigma cognitivo relega a um plano inferior os processos sociais de produção, distribuição, intercâmbio e consumo de informação, indicado somente por seus efeitos nas representações de geradores de imagens atomizadas (FROHMANN, 1995);

- c) a Cl necessita de um paradigma que não seja simplesmente pensado dos processos teóricos para a prática como uma espécie de 'adivinhação das necessidades de informação e perspectivas de satisfação dos usuários', mas de um processo que seja pensado a partir dos contextos práticos e empíricos para se fortalecer como fundamento teórico aplicável, viável e contíguo as necessidades de informação do cotidiano dos usuários;

- d) um novo paradigma deve ser pensado na possibilidade de incentivar uma autonomia dos usuários da informação ${ }^{\mathbf{5}}$ em que tenham capacidade e motivação para decidir os processos construtivos de informação (pensar uma construção coletiva e plural de informação).

O uso do título deste tópico 'em busca do paradigma social na Ciência da Informação' indica que é um paradigma que já se estabelece como fundamento teórico-epistemológico da área, mas ainda não está efetivamente consolidado em termos de percepções teóricas e práticas, o que permite afirmar que o paradigma social pode ser configurado como um paradigma emergente.

Contudo, é pertinente considerar que o paradigma social da $\mathrm{Cl}$ já teve um efetivo ponto de partida desde a década de 90, especialmente a partir dos estudos de Hjørland e Albrechtsen (1995) e Højrland (1997, 1998, 2000, 2002, 2003, 2003a,) que também denominam de paradigma sócio-cognitivo, o que conota sua construção/fundamentação recente e, por conseguinte, o desenvolvimento de estudos teórico-práticos visando a sua efetiva aplicabilidade.

Para fundamentar de forma mais precisa a constituição do paradigma social (ou sócio-cognitivo) da $\mathrm{Cl}$ define-se dois contextos: o primeiro é o da domain analysis (análise de domínio) de Birger Hjorland/Hanne Albrechtsen e o segundo é referente à Hermenêutica da informação de Rafael Capurro.

Em relação à análise de domínio é uma percepção teórica que se fundamenta a partir do conceito de domínio. Para Hjorland e Albrechtsen (1995, p. 400) o domínio se configura como "[...] comunidades do pensamento ou do discurso, que são partes de divisão da sociedade do trabalho." O conceito apresentado mostra que os autores trabalham em duas perspectivas gerais: a primeira se refere à significação do paradigma da análise de domínio e suas possibilidades de aplicação à $\mathrm{Cl}$, e a segunda indica que os termos 'análise de domínio' e 'comunidades discursivas' são diferentes, embora sejam complementares, uma vez que um domínio pode ser considerado como um tipo de comunidade discursiva.

Com essa definição, os autores contrapõem a percepção do paradigma cognitivo em conceber o desenvolvimento de estudos de forma isolada ou de buscar a partir da concepção de mapas cognitivos, processos ou modelos mentais, representar os discursos de uma área do conhecimento (neste caso a $\mathrm{Cl}$ ), mostrando que a análise do domínio se constitui no âmbito das prerrogativas institucionais, materiais e sociais de domínio de uma comunidade, pois segundo afirma Hjorland (1997), as comunidades discursivas podem ser identificadas em uma tessitura científica, acadêmica ou profissional que se estabelecem em estruturas de comunicação e publicação, tipos de documentos, terminologias específicas e estruturas informacionais particulares (estas estruturas informacionais desenvolvem processos de organização do conhecimento, padrões de cooperação, formas de linguagem e comunicação, sistemas de informação, literatura e sua distribuição e critérios de relevância).

Destarte, Hjørland (1997) afirma que a unidade de análise da Ciência da Informação é formada por campos coletivos de conhecimento (também chamados de domínios do conhecimento) referentes às suas comunidades discursivas (discourse communities) que não são entidades autônomas, mas se configuram em diferentes construções sociais empreendidas por indivíduos que estão ligados em pensamento, linguagem e conhecimento no contexto da sociedade moderna e concatenados às dimensões culturais e sociais.

Ressalta-se ainda que os estudos e conceitos sobre análise do domínio e comunidades discursivas não são únicos, definitivos e limitadamente aplicados na $\mathrm{Cl}$, pois abrem um leque de oportunidades para o desenvolvimento de 
estudos e práticas para amadurecimento e consolidação do paradigma social. A prova de que o conceito de domínio não é único na Cl reside na argumentação de Tennis (2003, p. 191-192, tradução nossa):

\begin{abstract}
Há uma série de conceitos semelhantes ao de domínios em Ciência da Informação como as Comunidades de Prática e as Comunidades Epistêmicas. Parece evidente para o leitor casual que, o domínio de um pode ser uma área de especialização, um corpo de literatura, ou mesmo um sistema de pessoas e práticas de trabalho com uma linguagem comum. No entanto, nenhum destes parâmetros do senso comum se prestam a definição suscinta. Cada uma delas se presta a operacionalização (definição no contexto de um estudo de investigação), mas não a definição - e mais especificamente a definição transferível (potencialmente útil em estudos de investigação).
\end{abstract}

A citação acima mostra que o conceito de domínio não somente não é único na $\mathrm{Cl}$, como ainda é um conceito em construção e que necessita de solidificação teórica no âmbito das investigações em $\mathrm{Cl}$, pois, ao que parece, conceitos de domínio, comunidades de prática e comunidades epistemológicas são muito mais contextualizadas no ambiente cotidiano de trabalho do que propriamente como linha de investigação científica, embora seja possível observar sua pertinência e importância como linha de pesquisa e, especialmente, para construção do paradigma social da Cl.

Já o conceito de análise de domínio é amplamente passível de investigação e aplicação na $\mathrm{Cl}$, Hjorland e Albrechtsen (1995) estabelecem criteriosa revisão de literatura e verificam os conceitos de domínio ligados/aplicados a outros termos, como especialidade/disciplina/ambiente, o que significa dizer que o domínio pode ser caracterizado como uma linha de investigação social da $\mathrm{Cl}$ com múltiplas percepções e aplicações. Hjørland (2002) indica que a análise do domínio deve ser analisada de forma intrinsecamente concatenada as linhas de investigação dessa área. Para tanto, descreve onze fundamentos em que a análise do domínio pode ser investigada na $\mathrm{Cl}$ :

- a) produção de guias de literatura e portais temáticos - publicações que listam e descrevem os sistemas de fontes de informação em uma ou mais áreas; organizam fontes de informação de um domínio de acordo com os tipos e funções abrangidas;

- b) produção de classificações e tesauros especiais - vocabulários específicos e estruturas lógicas de categorias e conceitos de um documento ou domínio, assim como as relações semânticas entre os conceitos;

- c) especialidades em indexação e recuperação - primam pela organização de simples documentos ou coleções de maneira a otimizar a capacidade de recuperação e visibilidade de seus 'potenciais epistemológicos;

- d) estudos empíricos de usuários - estudos de domínios de acordo com as preferências, comportamentos ou modelos mentais de seus usuários;

- e) estudos bibliométricos - padrões sociológicos explícitos entre documentos Individuais;

- f) estudos históricos - relacionam as influências mútuas entre a história do domínio ou assunto com tradições, paradigmas, assim como documentos, categorias, sistemas de comunicação e formas de expressão;

- g) estudos sobre documentos e gênero - revelam a organização e a estrutura de diferentes tipos de documentos em um domínio;

- h) estudos críticos e epistemológicos - organizam o conhecimento de um domínio em 'paradigmas' de acordo com suas suposições básicas sobre conhecimento e realidade; 
- $\quad$ estudos terminológicos, linguagens para propósitos especiais e estudos do discurso palavras, textos e expressões em um domínio de acordo com a semântica e critérios pragmáticos;

- i) estudos em estruturas e instituições em comunicação científica - organizam os principais atores e instituições de acordo com a divisão interna do trabalho em um domínio;

- j) análise de domínio na cognição profissional e inteligência artificial - modelos mentais de um domínio ou métodos de descoberta do conhecimento para produzir sistemas peritos.

Para promover maior precisão, as abordagens supramencionadas permitem classificar o estudo de análise de domínio em alguns fundamentos teóricos e científicos da Biblioteconomia/Cl, tais como: fundamentos de organização e tratamento da informação (produção de guias de literatura e portais temáticos, produção de classificações e tesauros especiais, especialidades em indexação e recuperação e estudos sobre documentos e gênero); fundamentos cognitivos e sociais (estudos empíricos de usuários e análise de domínio na cognição profissional e inteligência artificial); fundamentos históricos e epistemológicos (estudos históricos, estudos epistemológicos e crítica, estudos terminológicos, linguagens para propósitos especiais e estudos do discurso); fundamentos de ciência e pesquisa (estudos bibliométricos e estudos em estruturas e instituições em comunicação científica).

As abordagens propostas por Hjorland (2002) revelam que a Ciência da Informação independente dos seus fundamentos de estudo pode primar por um processo de construção social a partir de um determinado domínio das comunidades de discurso. As relações entre análise de domínio e os fundamentos organizacional, cognitivo-social, histórico-epistemológico e de ciência/pesquisa denotam que os estudos em Ciência da Informação devem primar por uma construção empírica, coletiva, interacionista e plural no âmbito de suas dimensões científico-institucionais e sociais.

A respeito da hermenêutica da informação indica-se que é uma percepção, que pode ser compreendida nos fundamentos teóricos da $\mathrm{Cl}$ relacionada aos procedimentos para construção de informação. Capurro (2003, p. 12) revela que:

\begin{abstract}
A hermenêutica como paradigma da ciência da informação postula justamente a diferença entre pré-compreensão, oferta de sentido e seleção, tomando como marco de referência, não a précompreensão de um sujeito ou usuário isolado, mas a de determinada comunidade assim como a de um campo específico de conhecimento e/ou de ação no qual o usuário está já implícita ou explicitamente inserido.
\end{abstract}

A hermenêutica da informação implica em um processo histórico e social de construção da informação, o que implica relacioná-la aos pressupostos do construtivismo e também de pressupostos do sócio-interacionismo (ou teria sóciohistórica). 6

A pré-compreensão se configura como instrumento inicial de interação social entre as comunidades discursivas (ou integrantes de uma comunidade discursiva) firmando uma crítica ao paradigma cognitivo do sujeito isolado, sem apresentar uma efetiva relação com o contexto social em que está inserido. A oferta de sentido e a seleção de sentido é um paradoxo fundamental a ser elucidado, de sorte que a oferta de sentido implica na composição de uma mensagem (emissão de notícia ou conteúdo) que não necessariamente demanda uma interação entre indivíduos, enquanto a seleção de sentido se aplica nos diversos procedimentos de uso, apreensão e apropriação da informação, a partir das interações entre usuário e sistema, o que implica na autonomia do usuário em selecionar/escolher aquilo que considera mais viável para construção da informação (consolidação do processo de compreensão). 


\section{Conclusão}

A Cl pode ser reconhecida como campo do conhecimento em intenso processo de construção teórica, histórica e epistemológica, sendo a reflexão/aplicação do conceito de paradigma um dos principais expoentes para consolidação epistemológica da área em caráter nacional e global. A noção de paradigma, embora tenha um efetivo firmamento teórico a partir das ideias de Kuhn se desenvolveu em caráter global, dada o seu amplo diálogo e contiguidade com a realidade social, assim como por suas variadas possibilidades de aplicação nas áreas do conhecimento científico, seja das ciências humanas e sociais, seja das ciências naturais e exatas.

A efetividade da aplicação das percepções de paradigma na $\mathrm{Cl}$ ocorre a partir da formação dos paradigmas físicos, cognitivos e sociais, que designaram perspectivas epistemológicas da área em diversos setores, tais como: organização e tratamento da informação, gestão da informação, tecnologias de informação e de comunicação, fontes e recursos de informação, estudo de usuários da informação, processos e fluxos de informação, entre outros.

Em particular, o paradigma cognitivo na Ciência da Informação se estabeleceu a partir de diversas correntes teóricas, com o behaviorismo, funcionalismo e estruturalismo, sendo de vital importância para os estudos da $\mathrm{Cl}$ e ainda hoje pode ser evidenciado com muita ênfase nos estudos sobre sistemas de recuperação de informação e estudo de usuários da informação.

Todavia, é pertinente considerar que o paradigma cognitivo não responde mais alguns problemas e desafios vivenciados pela $\mathrm{Cl}$ de ordem eminentemente social. Neste momento, o paradigma social surge com forte apelo para preencher lacunas e contribuir na construção de novos conhecimentos, pois além de observar o usuário como ponto central, busca construir a informação de forma coletiva e interacionista observando as diversas possibilidades de domínio e interpretação, e promovendo autonomia aos usuários da informação em termos de escolhas e, principalmente, nos processos de uso, apreensão e apropriação de informação.

Portanto, o ideário de paradigma na $\mathrm{Cl}$ já é reconhecidamente consolidado na área, logo o paradigma social ainda é uma questão em franco processo de construção, que caminha na constituição de fundamentos de domínios de uma comunidade discursiva e na hermenêutica da informação. Mas acima de tudo, é pertinente considerar que o paradigma social dá margem para a criação de novas percepções, interpretações e contribuições ad infinitum, visando amadurecer os estudos teóricos, epistemológicos e empíricos da $\mathrm{Cl}$.

\section{Bibliografía}

ARAÚJO, C. A. A. Correntes teóricas da ciência da informação. Ciência da Informação, Brasília, DF, v. 38, n.3, p. $192-204,2009$.

BAPTISTA, S. G.; CUNHA, M. B. Estudos de usuários: visão global dos métodos de coleta de dados. Perspectivas em Ciência da Informação, Brasília, DF, v. 12, n. 2, p. 168-184, maio/ago., 2007.

BELKIN, N. J. Anomalous State of Knowledge as basis for information retrieval. The Canadian Journal of Information Science, Toronto, v. 5, p. 133-143, 1980.

BeRTALANFFY, L. V. Teoria Geral dos Sistemas. In: BIRnBAuM, P.; CHAZEL, F. Teoria Sociológica. São Paulo: Hucitec-Edusp, 1977.

BRIER, S. What is a Possible Ontological and Epistemological Framework for a True Universal 'Information Science'? The Suggestion of a Cybersemiotics. In: Hofkirchner, W. (Ed.). The Quest for a Unified Theory of Information: Proceedings of the Second International Conference on the Fundations of Information Science. Amsterdam: Gordon and Breach, p. 79-99, 1999.

BROOKES, B. C. The developing cognitive view in information science. In: International Workshop on the Cognitive Viewpoint, Anais ... p. 195-203, 1977.

The foundations of Information Science. Journal of Information Science, Amsterdam, v. 2, p, 125-133, 1980. 
CAPRA, F. A teia da vida: uma nova compreensão científica dos sistemas vivos. Tradução de Newton Roberval Eichemberg. São Paulo: Editora Cultrix, 1996.

CAPURRO, R. Epistemologia e Ciência da informação. In: V ENCONTRO NACIONAL DE PESQUISA EM CIÊNCIA DA INFORMAÇÃO, 5., Belo Horizonte, 2003. Anais... Belo Horizonte: Escola de Ciência da Informação da UFMG, 2003. 1 cd-rom.

CARVALHO, L. A. V. Teoria da Mente: a alma humana em busca de si mesma. In: Fuks, S. (Org.), Descartes 400 anos: um legado científico e filosófico. Rio de Janeiro: Relume Dumará, 1998. p. 201-215.

CARVALHO SILVA, J. L. Normatividade, tecnicidade e/ou cientificidade da Biblioteconomia. TransInformação, Campinas, v. 25, n. 1, p.5-17, jan./abr. 2013. Disponível em: < http://periodicos.puc-campinas.edu.br/seer/index.php/transinfo/article/view/1783/1707 >. Acesso em: 8 abril 2013.

Necessidades de informação e satisfação do usuário: algumas considerações no âmbito dos usuários da informação. InCID: R. Ci. Inf. e Doc., Ribeirão Preto, v. 3, n. 2, p. 102-123, jul./dez. 2012. Disponível em: <http://www.revistas.usp.br/incid/article/view/48656/52727>. Acesso em: 21 jan. 2013.

; FREIRE, G. H. de A. Um olhar sobre a origem da ciência da informação: indícios embrionários para sua caracterização identitária. Encontros Bibli, Florianópolis, v.17, n.33, p.1-29, 2012. Disponível em: < http://www.periodicos.ufsc.br >. Acesso em: 11 maio 2012.

DE MAY, M. The cognitive viewpoint: its development and its scope. In: CC 77: INTERNATIONAL WORKSHOP ON THE COGNITIVE VIEWPOINT, 1977, Gent. Proceedings... Gent: Gent University, p. 24-32.

FIGUEIREDO, N. M. de. Estudos de uso e usuários da informação. Brasília: Ibict, 1994.

FREIRE, P. Educação como prática da liberdade. 23. ed. Rio de Janeiro: Paz e Terra, 1999.

Pedagogia da autonomia: saberes necessários à prática educativa. 35. ed. São Paulo: Paz e Terra, 1996.

. Pedagogia do oprimido. 32. ed. Rio de Janeiro: Paz e Terra, 2002.

GONZÁLEZ, F. ¿Que es un paradigma? Análisis teórico, conceptual y psicolingüístico del término. Investigación y Postgrado, Caracas, v. 20, n.1, p. 1-25, abr. 2005. Disponível em:< http://www.scielo.org.ve/scielo.php?pid=S1316$00872005000100002 \&$ script=sci arttext >. Acesso em: 01 fev. 2013.

HJØRLAND, B. Domain analysis in information science: Eleven approaches - traditional as well as innovative. Journal of Documentation. [S.I.], v.58. n.4, p. 422-462, 2002.

Epistemology and the Socio-Cognitive Perspective in Information Science. Journal of the American Society for Information Science and Technology, [S.I.], v.53, n.4, p. 257-270, 2003.

Information seeking and subject representation: an activity-theoretical approach to Information Science. New York: Greenwood Press, 1997.

Library and information science: practice, theory, and philosophical basis. Information Processing and Mangement, [S.I.], v. 36, p. 501-531, 2000.

Principia Informatica: Foundational Theory of Information and Principles of Information Services. In: Bruce, H.; Fidel, R; Ingwersen, P.; Vakkari, P. (Eds.): Emeerging Frameworks and Methods: Proceedings of the Fourth Conference on Conceptions of Library and Information Science (CoLIS4). Greenwood Village, Colorado: Libraries Unlimited, 2003a. p. 109-121. 621, 1998.

Theory and Metatheory of Information Science: A New Interpretation. Journal of Documentation, [S.I.], v. 45, n. 5, p. 606-

; ALBRECHTSEN, H. Toward a new horizon in information science: domain-analysis. Journal of the American Society for Information Science, New York, v.46, n.6, p.400-425, 1995.

INGWERSEN, P. Information retrieval interaction. London: Taylor Graham, 1992.

KUHN, T. S. A estrutura das revoluções científicas. Tradução de Beatriz Vianna Boeira e Nelson Boeira. 3. ed. São. Paulo: Perspectiva, 1992. $257 \mathrm{p}$.

MALINOWSKI, B. A Teoria Funcional. In BIRNBAUM, P. \& CHAZEL. Teoria Sociológica. São Paul: HUCITEC-EDUSP, 1977. 
MARTELETO, M. R. Informação: elemento regulador dos sistemas, fator de mudança social ou fenômeno pós-moderno? Ciência da Informação, Brasília, v.16, n.2, p. 169-181, 1987.

MERTON, R. K. Social Theory and Social Structure. Illinois: Glencoe (revised edition), 1957.

NASCIMENTO, D. M. A abordagem sócio-cultural da informação. João Pessoa, Informação \& Socidade: Estudos, João Pessoa, v.16, n.2, p.25-35, jul./dez. 2006.

OSTERMANN, F. A epistemologia de Kuhn. Cad. Cat. Ens. Fis., Florianópolis, v.13, n. 3, p.184-196, dez./1996.

PINHEIRO, L. V. R. Usuário - informação: o contexto da ciência e da tecnologia. Rio de Janeiro: LTC/IBICT, 1982.

TENNIS, J. T. Two Axes of Domains for Domain Analysis. Knowledge Organization Journal. Washington, v. 30, n. 3/4, p. 191-195, 2003.

SARACEVIC, T. Interdisciplinary nature of information science. Ciência da Informação, Brasília, DF, v. 24, n. 1, p. 36-41, 1995.

SANTOS, B. de S. Um discurso sobre as ciências na transição para uma ciência pós-moderna. Estudos Avançados, São Paulo, v. 2, n.2, p. 46-70, aug./1988.

WATSON, J. B. Psychology from the stand point of view of a Behaviorist. Toronto: Philadelphia Lippincott, 1912.

WERSIG, G. Information science: the study of postmodern knowledge usage. Information Processing \& Management, Berlim, v.29, n.2, p.229-239, 1993.

WILSON-DAVIS, K. The Centre for Research on Users Studies: aims and functions. Asilib Proceedings, Sheffield, v. 29, n. 2, p. 6569 , fev./1977.

\section{Dados dos autores}

\section{Jonathas Luiz Carvalho Silva}

Professor do curso de Biblioteconomia da Universidade Federal do Ceará - Campus Cariri. Mestre em Ciência da Informação pela Universidade Federal da Paraíba. Doutorando em Ciência da Informação pela Universidade Federal da Bahia. Tem experiência na área de Ciência da Informação, com ênfase em Biblioteconomia, atuando principalmente nos seguintes temas: identidade social e cultural, identidade da Biblioteconomia brasileira e aspectos teóricos, históricos e epistemológicos da Biblioteconomia e da Ciência da Informação. Trabalha ainda enfaticamente com projetos sociais, especialmente a partir das bibliotecas escolares, comunitárias e populares, interagindo com diversos movimentos sociais e comunitários e concebendo suas concepções sociais, educativas e culturais. Tem atuado enfaticamente no ensino e pesquisa com projetos, disciplinas, palestras e cursos no contexto da ciência e metodologia da pesquisa. Apresenta também estudos e reflexões sobre usuários da informação.

jonathascarvalhos@yahoo.com.br

\section{Maria Giovanna Guedes Farias}

Doutoranda do Programa de Pós-Graduação em Ciência da Informação da Universidade Federal da Bahia. Mestre em Ciência da Informação pelo Programa de Pós-Graduação em Ciência da Informação pela Universidade Federal da Paraíba.Graduada em Comunicação Social (Habilitação: Jornalismo) pela Universidade Estadual da Paraíba. Curso de especialização em Marketing e Novas Mídias promovido pelo Umweltzentrum des Handwerkskammer Trier - Alemanha (2003). Experiência de sete anos em assessoria de imprensa, redação de revistas, jornais impressos e on-line.

mgiovannaguedes@gmail.com

$\begin{array}{ll}\text { Recebido-Received } & : 2013-04-08 \\ \text { Aceito-Accepted } & : 2013-06-30\end{array}$




\section{(c) $\mathbf{E Y}$ New articles in this journal are licensed under a Creative Commons Attribution 3.0} United States License.

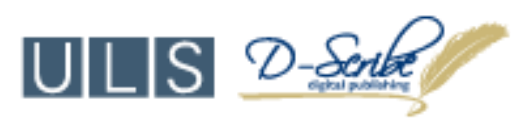

This journal is published by the University Library System of the University of Pittsburgh as part of its D-Scribe Digital Publishing Program and is cosponsored by the University of Pittsburgh Press.

1 Kuhn (1992, p. 29) denomina 'ciência normal' como a "[...] pesquisa firmemente baseada em uma ou mais realizações científicas passadas. Essas realizações são reconhecidas durante algum tempo por alguma comunidade científica específica como proporcionando os fundamentos para sua prática posterior".

2 Com base na teoria de Belkin, o dinamarquês Ingwersen (1992) desenvolveu a Teoria dos Modelos Mentais aplicada a recuperação da informação (Teoria Cognitiva da Recuperação da Informação), que pressupõe a interação entre geradores do Sistema de Informação, autores dos documentos, profissionais da informação - intermediário humano - e usuários dentro de um campo de assunto, que compartilham as mesmas estruturas de conhecimento, com vistas a promoção de uma recuperação de informação eficiente e eficaz.

3 Popper (1972) estabelece uma esquematização ontológica contemplando três mundos que podem ser assim definidos: a) O mundo um é dos objetos e estados físicos; b) O mundo dois compreende os estados de consciência; e c) O mundo três integra o conhecimento objetivo agregando a informação.

4 Porém, Pinheiro (1982) destaca que os resultados obtidos não foram os almejados, principalmente devido à complexidade de se determinar o comportamento e as necessidades de informação dos usuários.

5 Considerando a autonomia, a capacidade do indivíduo em agir de forma emancipada e crítica buscando estabelecer, de um lado, suas próprias ideias e expor suas próprias opiniões e, por outro lado, respeitando a opinião alheia e agindo com responsabilidade. (FREIRE, 1996, 1999, 2002).

6 Capurro (2003) também fala que a hermenêutica da informação está ligada a semiótica e a cibernética de segunda ordem. Essa relação disciplinar possibilita uma integração dos aportes e metodologias do paradigma físico e cognitivo, visando suas inserções em uma dimensão social. Essa relação entre semiótica e cibernética de segunda ordem forma o que Brier (1999) chama de 'cybersemiotics'. 